\title{
O Desempenho dos Postos de AtENDIMENTO aO TrabalHador na Perspectiva dos EMpregadores da Região Bragantina (SP)
}

Dércia Antunes de Souza

MestreemAdministração pło IMES/ USCS - Universidade Municipal deSão Całanodb Sul, Pós-Graduada emGestão de Pessoas pda UnivesidadeSão FranciscoeDocettena FAEX FaaildadedeExtremaMG ena FATEC - Faculdadede Teendoja da Informação emBracanca PaulistaSP daciaantume@ud.combr

Antonio Carlos Gil Datoradoem SaúdePública pda UniversidadedeSão Paulo Datoradopda Fundação Escda deSoidogja ePdítica deSão Paulo MestradbemCiênia Pdítica eSodidoga pda Fundação Escda deSocidogja ePdítica deSãoPaulo eProfessor da UnivesidadeMuniaipal deSãoCałanodbSul acji@@ud.combr

\section{ResumO}

\section{ABSTRACT}

Esta pesquisa tem como objetivo analisar a percepção dos empregadores acerca do desempenho do Posto de Atendimento ao Trabalhador (PAT) das cidades de Bragança Paulista, Atibaia e Itatiba. Consiste num levantamento de campo realizado com uma amostra de 100 clientes empresas. Conclui-se que os PATs são identificados com a intermediação de mão de obra pouco qualificada, já que a maioria dos candidatos que os procuram são pessoas de baixa renda e baixo nível de escolaridade. Esse fato pode estar indicando deficiência dos PATs, que não são reconhecidos pelas empresas como entidades adequadas para o suprimento de suas necessidades de pessoal nos mais diversos níveis. Mas pode também estar indicando a relevância social dos serviços dos PATs, já que para grandes contingentes de trabalhadores, eles constituem o principal, senão o único elo com 0 mercado de trabalho.

Palavras-chave: Emprego. Intermediação de Mão de O bra. Posto de Atendimento ao Trabalhador (PAT).
This reserch ains toanalyzepereptions of employes abait theperformance of carer centersin the dities of Bragança Paulista, Atibaia and Itatiba, in theSãoPaulo State It consists of a fidd surveycondurted with a sample of 100 companies It vas conduded that theca reer centess are identified as a mediation place of undkilled workess sincemost of thecandidates who sek themare of lessadkantaged soiceconomicgraupsand eeturational led. This fad may indicatean inadequagy of caner centers which arend reognized by companies as approprateentities to supply their neels for personnd at varias levds But it alsodemonstrates thesoial redeance of theservice offe reel by thesecentes, sinefor a largenumbers of workers this is the nain, if not theorly, link with thelabor marke.

Keywords: Emplgment. WorkforeIntemmelation Career Centers 


\section{INTRODUÇÃO}

O desemprego constitui uma das maiorespreocupações dos brasileiros. É o que indicam os resultados de levantamentos realizados em vários pontos do País (MARCHI, 2008; FOLHA ONLINE, 2008). Com efeito, o problema do desemprego pode ser facilmente compreendido como um dos que mais afligem a população, já que a maioria das pessoas depende dele para a sua sobrevivência. Por essa razão é que os organismos internacionais especializados, como a Organização Internacional do Trabalho, os governos nacionais, os sindicatos de trabalhadores e as organizações da sociedade civil, dedicam especial atenção ao problema do emprego.

Não apenas no Brasil, mas em praticamente todo 0 mundo intensifica-se a discussão acerca do emprego e consequentemente das políticas públicas de emprego. Com 0 advento da globalização, a rapidez das transformações tecnológicas e a reestruturação produtiva, o País vem enfrentando o fenômeno do desemprego, que se caracteriza como de natureza estrutural e de longo prazo, como também a incapacidade do sistema produtivo em gerar mais e bons empregos na velocidade requerida pela internacionalização da economia (CHAHAD; CACCIAMALI, 2003).

As mudanças nas estruturas produtivas trazem profundas consequências para o mundo do emprego. Com frequência, as novas formas de gestão de mão de obra implicam diminuição de postos de trabalho e elevação dos níveis de desemprego. Daí a necessidade de políticas públicas para o setor.

O Brasil tem uma história de atuação do Poder Público no mundo do trabalho, que, a rigor, inicia-se com a Consolidação das Leis do Trabalho, na década de 1930. D urante muito tempo a atuação do setor público centrou-se na defesa dos direitos do trabalhador. Assim, merece especial destaque a criação do Sistema Nacional de Emprego (SINE), em 1975. A principal finalidade do SINE na época era promover a intermediação de mão de obra, implantando serviços e agências de colocação em todo o País por meio de postos de atendimento. O utras políticas foram confiadas ao SINE ao longo das últimas décadas, mas as ações referentes à intermediação de mão de obra continuam sendo a face mais visível do sistema.

A intermediação de mão de obra constitui um dos eixos das políticas ativas implementadas no âmbito do Sistema Público do Trabalho, Emprego e Renda, que se tornou importante elemento para maximizar as oportunidades de empregos de qualidade e democratizar as possibilidades de acesso a essas vagas. Trata-se de um programa que tem como propósito propiciar informações e orientações ao trabalhador na procura por emprego e possibilitar a sua (re)colocação nas vagas disponibilizadas pelas empresas. (SINE , 2008).

O SINE desenvolve a atuação relativa à intermediação de mão de obra por intermédio dos Postos de Atendimento ao Trabalhador (PATs) existentes em mais de mil municípios brasileiros. Esses PATs são integrados à estrutura dos governos estaduais e funcionam em instalações das prefeituras municipais com o apoio de funcionários dessa esfera de governo. Os postos fazem a captação de vagas em empresas, bem como o cadastramento de pessoas que estejam procurando uma ocupação e o encaminhamento dos trabalhadores cadastrados para participarem de processos seletivos nas empresas. D essa forma, os PATs procuram facilitar o processo de contratação e o acesso às oportunidades de emprego.

A intermediação de mão de obra constitui uma das mais importantes formas de efetivação das políticas ativas de emprego. Assim, foram desenvolvidas pesquisas em diferentes localidades com vistas a analisar a atuação de PATs (NUNES, 2003; GOLLER, 2000; MORETTO, 2007; RADZINSKI, 2008). Mas torna-se necessária também a realização de pesquisas com a finalidade de verificar como os trabalhadores, os empresários e os mais diversos segmentos da sociedade civil avaliam o SINE.

Na esteira dessas preocupações é que foi realizada em 2008 a pesquisa aqui relatada, cujo propósito foi o de verificar como os profissionais que atuam no âmbito das empresas vêem o trabalho dos postos em relação à intermediação de mão de obra, especificamente na região compreendida pelos municípios de Bragança Paulista, A tibaia e Itatiba, que constitui hoje uma das áreas geográficas do Estado de São Paulo que apresentam maiores níveis de crescimento tanto em termos de população quanto de emprego. Para tanto, foram definidos os seguintes objetivos:

1) D escrever as atividades relativas à intermediação de mão de obra nos PATs da região;

2) Caracterizar as empresas da região que procuram os serviços de intermediação de mão de obra;

3) Identificar a opinião dos profissionais de $\mathrm{RH}$ dessas empresas acerca da qualificação dos candidatos encaminhados pelos PATs;

4) Identificar a opinião dos profissionais de $\mathrm{RH}$ sobre a adequação dos PATs às suas necessidades;

5) Identificar a opinião dos profissionais de $\mathrm{RH}$ a respeito do atendimento proporcionado pelos PATs.

\section{REFERENCIAL TEÓRICO}

\subsection{Politicas públicas de emprego}

Mediante políticas públicas, o Poder Público toma medidas capazes de afetar o nível de emprego, que vão desde a fixação do salário mínimo até a formação profissional. Nesse aspecto, é possível identificar dois tipos de instrumentos ou medidas: as ativas e as passivas. Essas ações são definidas como políticas públicas de emprego e podem ser classificadas em políticas ativas e passivas As políticas ativas consideram o nível de emprego como dado e seus objetivos são os de assistir financeiramente 0 trabalhador desempregado. As políticas passivas destinam-se a cobrir os gastos com benefícios aos desempregados e programas de aposentadoria do trabalhador (OECD, 1994).

Os instrumentos clássicos das políticas ativas são o seguro-desemprego, a indenização aos trabalhadores desligados e os programas assistenciais para quem não tem acesso ao seguro, à intermediação de mão de obra e ao Fundo de Garantia por Tempo de Serviço (FGTS). Essas políticas po- 
dem ser de dois tipos: ativas pela oferta e ativas pela demanda. As políticas ativas pela oferta têm como instrumentos típicos: planos de incentivo à aposentadoria antecipada de trabalhadores desempregados, manutenção de jovens no sistema escolar, fomento à migração, expulsão de populações, e programas de formação e reciclagem profissional. As políticas ativas pela demanda, por sua vez, têm como mecanismos: criação de empregos públicos, investimentos emergenciais nas frentes de trabalho, subsídios públicos à contratação, oferta de crédito para micro e pequenas empresas, redução de jornada de trabalho, e incentivo ao trabalho autônomo (AZERED 0; RAMO S, 1995).

A experiência brasileira no campo das políticas pública de emprego começou a ser implantada na década de 1960. Nessa época, o crescimento populacional, a migração rural, e 0 crescimento dos grandes centros urbanos, provocaram uma expansão significativa da mão de obra disponível nas cidades. As altas taxas de crescimento econômico do período possibilitaram a incorporação de parcelas expressivas da População Economicamente Ativa (PEA) ao mercado formal de trabalho, sobretudo no setor industrial e nos aparelhos de Estado. Nesse período, a economia mundial caracterizava-se por um surto de crescimento econômico sem precedentes. Acreditava-se, então, que a melhoria das condições de vida da população seria consequência direta do crescimento econômico. 0 desemprego existente era entendido como uma imperfeição decorrente do baixo nível de desenvolvimento econômico do País. Assim, o predomínio dessa concepção parece explicar a quase ausência no Brasil de programas públicos de emprego e renda ainda no decorrer dos anos 1960 e 1970 (IPEA, 2006).

0 debate acerca das políticas de mercado de trabalho intensificou-se na década de 1990, como decorrência, em grande medida, da piora do desempenho do mercado de trabalho nesse período, especialmente pelo intenso e crescente desemprego que atingiu parcela expressiva da população em idade ativa, com ênfase maior sobre alguns segmentos, como jovens e mulheres. Até 1980, a despeito da existência de algumas políticas nessa área, como a intermediação de mão de obra e as experiências de qualificação da mão de obra, a execução das políticas de emprego esteve relegada a um plano secundário, sobretudo pelo dinamismo da economia na geração de postos de trabalho. Na década de 1980, com 0 surgimento do desemprego aberto como problema relevante do mercado de trabalho, a principal medida foi a criação do seguro-desemprego. Foi nos anos 1990, no entanto, com a instituição do Fundo de Amparo ao Trabalhador (FAT), criado para financiar o seguro-desemprego, que se criaram condições financeiras para o financiamento para as políticas de mercado de trabalho.

A ênfase nessas políticas constituiu-se como resposta à crise do emprego resultante das diretrizes da política macroeconômica implementada a partir do governo Collor, que privilegiou o combate à inflação e a regulação econômica pelo mercado. As medidas mais enfatizadas foram a intermediação de mão de obra, a qualificação profissional, além do segurodesemprego. A elas, vieram a se somar os programas de gera- ção de emprego e renda, incluindo, além das atividades de fomento às micro e pequenas empresas e ao trabalho autônomo, as iniciativas no campo da economia solidária e 0 microcrédito (POCHMANN; MORETTO, 2004).

Da análise das políticas públicas de emprego no Brasil depreende-se que as políticas reativas ou passivas é que têm constituído o eixo prioritário das intervenções públicas sobre o mercado de trabalho brasileiro. Isso porque no Brasil a questão da pobreza não está necessariamente vinculada à questão do emprego. Assim, a pobreza tende a ser combatida com políticas específicas que não se relacionam diretamente com ações voltadas para o mercado de trabalho, como as políticas de previdência e renda. Essa ênfase no combate à pobreza contribui para fragilizar a inclusão de políticas de emprego no interior das políticas sociais (DIEE SE, 2001).

O Estado contemporâneo não se sente mais responsável pelo pleno emprego. As corporações transnacionais também não. Mas os Estados nacionais vêm sendo chamados em toda parte a garantir a sobrevivência dos cidadãos, que estão sendo expulsos em grande quantidade do trabalho formal. Assim, ocorre aquilo que Dupas (2003) chama de "efeito democracia": à medida que aumenta o número de desempregados e de pobres, cresce sua base política. Introduz-se, assim, clara dissonância entre o discurso liberalizante das elites e sua práxis política. Enquanto isso, a questão quanto ao futuro do papel dos Estados nacionais continua em aberto, assim como a crescente disparidade entre as demandas sociais e a impossibilidade do Estado de atendê-las de modo convencional.

\subsection{Sistema Nacional de E mprego}

D esde 1950, a O rganização Internacional do Trabalho (O IT ), organismo vinculado à 0 rganização das Nações Unidas (O NU), vem recomendando, através da Convenção 88, que os países organizem sistemas públicos de emprego, instâncias de construção de políticas públicas destinadas a buscar garantir o direito ao emprego, no âmbito das políticas de proteção social (SOUZA, 2003, p. 185).

A primeira experiência de organização de um Sistema Público de Emprego no Brasil se constituiu em 1975, com a instituição do Sistema Nacional de Emprego - SINE, pelo Decreto Federal $n^{0}$ 76.403, de 08.10.1975. O SINE é coordenado e supervisionado pelo Ministério do Trabalho e Emprego, por intermédio da Secretaria de Emprego e Salário. Sua criação fundamenta-se na Convenção no 88/ 48 da O IT, que trata da organização dos serviços públicos de emprego, ratificada pelo Brasil. Sua descentralização para os Estados efetivou-se a partir de convênio firmado entre o Ministério do Trabalho e os Governos Estaduais (GO LLER, 2000).

A criação do SINE coincidiu com o fim do "Milagre Econômico", período em que se verificaram as mais altas taxas de crescimento do Produto Interno Bruto no País. A proposta do governo, à época, trazia a concepção de que 0 problema do desemprego seria resolvido por ajustes na oferta e na demanda do mercado de trabalho. Essa proposta baseava-se na ideia de que o dinamismo da economia brasileira teria oportunizado a criação suficiente de empregos. 0 que 
haveria, então, era a necessidade de ajuste das informações dos agentes econômicos e de adequado preparo de mão de obra do País (BORGES, 2003).

As ações essenciais do SINE são: 0 atendimento ao seguro-desemprego, a intermediação de mão de obra, a qualificação profissional, a geração de trabalho e renda, e a geração de informações sobre o mercado de trabalho. Essas ações requerem uma articulação entre a União, por meio do Ministério do Trabalho e Emprego; os Estados, por intermédio das Secretarias Estaduais do Trabalho; e os serviços, as agências, os postos e balcões de emprego, público ou privado. Assim, o SINE atua como um sistema integrado de órgãos e entidades, nos planos federal, estadual e municipal, que visa à prestação de serviços ao trabalhador com vistas à sua proteção e à melhoria nas condições de inserção e de permanência no mercado de trabalho (SOUZA, 2003).

O SINE nasceu com a ênfase principal nos processos de intermediação de mão de obra, como solução ao desemprego friccional. Essa intermediação é uma atividade que tem como objetivo apoiar as pessoas em busca de um emprego no mercado de trabalho. Para tanto, o SINE dispõe de informações junto aos seus postos de atendimento acerca das exigências dos empregadores ao disponibilizarem suas vagas. Busca-se, dessa forma, a redução dos custos e do tempo de espera tanto para o trabalhador quanto para o empregador.

Existem no Brasil mais de 1.100 postos de atendimento ao trabalhador do SINE, que cadastram por dia entre 75 mil e 80 mil trabalhadores. No período de 2002 a 2005, foram cadastrados mais de 4,5 milhões de trabalhadores. Foram inseridos, nesse período, dois milhões e 700 mil trabalhadores no mercado formal, trabalhando com carteira de trabalho assinada (FERRER, 2006).

\subsection{Intermediação de mão de obra}

A intermediação de mão de obra constitui um dos eixos das políticas ativas implementadas no âmbito do Sistema Público do Trabalho, Emprego e Renda, que se tornou importante elemento para maximizar as oportunidades de empregos de qualidade e democratizar as possibilidades de acesso a essas vagas. Trata-se de um programa que tem como propósito propiciar informações e orientações ao trabalhador na procura por emprego e também aos empregadores no suprimento de recursos humanos. O que o SINE procura é promover o encontro de ambos, auxiliando no recrutamento de trabalhadores por parte dos empregado res e na (re)colocação dos trabalhadores nas vagas disponíveis (SINE, 2007).

O s serviços de intermediação são estratégicos para auxiliar o desempregado a encontrar uma nova colocação no mercado de trabalho e, na perspectiva de Estado neoliberal, reduzir despesas com políticas compensatórias. Por sua vez, os serviços públicos de intermediação de emprego, quando executados diretamente pelo Estado, assumem um grande valor social, pois, além de auxiliarem o trabalhador na obtenção de um emprego, podem encaminhá-lo à qualificação profissional, para alternativas de geração de renda ou, ainda, para outros serviços públicos. 0 serviço de intermediação de mão de obra também constitui valioso instrumento de geração de informações sobre a demanda e a oferta de trabalho, local e estadual, assim como de desempenho do Sistema de Emprego (GOLLER, 2000).

Diversos fatores contribuíram para a implantação de um serviço público e para a existência de um serviço de intermediação de mão de obra. Segundo Moretto (2007), havia a necessidade de conferir maior transparência ao mercado de trabalho, uma vez que as bolsas de trabalho criadas por sindicatos e por empregadores geravam a desconfiança mútua entre capital e trabalho. 0 desemprego passou a ser reconhecido como fonte de pobreza e de mal-estar social, e como decorrência dos ciclos econômicos. Daí a necessidade de esforços voltados à redução de desemprego friccional e estrutural.

Ao contrário do que ocorre com o campo das políticas públicas referentes à arquitetura de serviços e concessão de benefícios, ainda são poucos os trabalhos que tratam da intermediação de mão de obra. Pode-se identificar, no entanto, pesquisas referentes à caracterização dos agentes do sistema de intermediação e dos demandantes do sistema (GUIMARÃES, 2005), e às atividades das empresas prestadoras de serviços de seleção, agenciamento e locação de mão de obra temporária (PAMPLONA, 2003).

Ao se contrastar as agências governamentais e sindicais com as agências privadas, percebe-se que a principal diferença está nas estratégias para capturar os demandantes, tais como: localização geográfica, formas de organização das atividades, configuração do layaut das agências, formas de atendimento ao pessoal, diversificação do staff e modalidades de treinamento, recursos computacionais, e sistema de informações que sustentam o trabalho do atendimento (G UIMARÃES, 2005).

A intermediação de mão de obra é um instrumento de Política Pública de combate ao desemprego prestado de forma gratuita pelo Sistema Nacional de Emprego, destinada à colocação ou inserção dos trabalhadores no mercado de trabalho, de maneira ágil, minimizando o custo social causado pelo desemprego. Azeredo (1998) identifica os serviços públicos de emprego como estratégicos para auxiliar com agilidade o desempregado a encontrar uma nova colocação no mercado de trabalho e, dessa forma, reduzir o desemprego friccional. Esse serviço é de fundamental importância para que o trabalhador tenha acesso de forma sistemática às vagas disponíveis no mercado e ao perfil requerido para seu preenchimento.

Cacciamali, Silva e Matos (1998, apud GO LLER, 2000) destacam que, do ponto de vista do mercado de trabalho, o SINE, como serviço público de intermediação, poderia concorrer com as agências privadas de emprego. No entanto, a concorrência não se estabelece em função da relevância social de uma agência pública de intermediação "desprendida de critérios empresariais de avaliação", enquanto as agências privadas de emprego têm objetivos com a intermediação, exclusivamente voltados à "lucratividade da operação" (p. 176).

Dessa forma, aintermediação realizada pelo SINE , além do papel precípuo de auxiliar o trabalhador na obtenção de um emprego, tem também o papel de diagnosticar suas carências pessoais e profissionais relacionadas com as possibi- 
lidades de obtenção de emprego, podendo encaminhá-lo à qualificação profissional, para alternativas de geração de renda ou, ainda, para outros serviços públicos (CACCIAMALI; SILVA; MATOS, 1998). As agências privadas de emprego têm sistemáticas de atendimento diferenciadas entre si e em relação aos Programas de Atendimento ao Trabalhador (PATs). As agências privadas de emprego são mais eficientes que os PATs, porque fazem uma seleção mais rigorosa para obter um melhor enquadramento profissional dos trabalhadores, são mais ágeis no encaminhamento e, apesar de onerarem as empresas, seu custo-benefício é positivo.

Segundo G oller (2000), o contingente de candidatos que buscam os serviços de intermediação de mão de obra dos PATs é constituído em sua maioria por trabalhadores de baixa escolaridade, sem experiência profissional, sem qualificação específica e com pouco tempo de experiência comprovada. Para esses trabalhadores, os PATs são seu elo com 0 mercado de trabalho. Dessa forma, os empregadores consideram que os PATs não têm condições de atender a uma demanda de trabalho mais qualificada, e ainda não observam todas as exigências do perfil do trabalhador solicitado, fazendo um encaminhamento inadequado.

Existem grupos de indivíduos com maiores dificuldades de acesso às informações do mercado de trabalho e menores recursos, o que impossibilita o uso de outros meios alternativos de busca de emprego. Segundo Radzinski (2008), as agências públicas, em sua maionia, estão voltadas para atender a base do mercado de trabalho, ou seja, a oferta e demanda por postos de trabalho que exigem menor qualificação e oferecem salários mais baixos. Para Guimarães (2005), são os trabalhadores muito pobres os que mais procuram emprego usando o sistema público. A própria formação e a baixa qualificação desses indivíduos pode ser um fator de defesa da existência de um serviço público de intermediação, quando a colocação de trabalhadores desse perfil não é do interesse de agências privadas de emprego nem mesmo pertence ao perfil de vagas oferecidas por essas empresas.

O s PATs assumem papel relevante como intermediador entre o trabalhador e as empresas, so bretudo para as micro e pequenas empresas, que, por serem de modo geral administradas diretamente pelo empregador, acabam por não ter um processo sistematizado de seleção e recrutamento de pessoal (NUNES, 2003). Assim sendo, a intermediação de mão de obra proporcionada pelos PATs possibilita a essas empresas o recrutamento e a seleção de candidatos como um serviço de apoio.

O s PATs ainda não conseguem desenvolver a contento suas tarefas. Para Guimarães (2005), a superficialidade e a rapidez da entrevista podem ser responsáveis pela menor chance de o candidato conseguir algumas das vagas disponíveis, por pouco explorar as chances que o sistema de informações abre no sentido de simular alvos alternativos pretendidos e, ao fazê-lo, aumentar a chance de localizar um posto de trabalho. Isso sugere a necessidade de que, no longo prazo, sejam avaliados os critérios para alocação de recursos. Mas Guimarães sugere também que, no curto prazo, sejam estimulados os procedimentos de (re)treinamento constante do pessoal envolvido na intermediação no sistema público, notadamente dos entrevistadores.

\section{METODOLOGIA}

\subsection{Tipo de pesquisa}

O presente estudo caracteriza-se como um levantamento de campo (survey), já que tem como objetivo distinguir as empresas que procuram os serviços de intermediação de mão de obra e verificar opiniões dos responsáveis pelo recrutamento de pessoal.

\subsection{População e amostra}

O universo da pesquisa é constituído pelas empresas dos municípios de Bragança Paulista, Atibaia e Itatiba que se valem dos serviços de intermediação de mão de obra proporcionados pelos PATs sediados nesses municípios. Em agosto de 2008, essa população era composta por 535 empresas.

A amostra da pesquisa é constituída por 100 empresas. Foi selecionada pelos critérios de acessibilidade e intencionalidade. Justifica-se a adoção desse tipo de amostragem em virtude das dificuldades para se obter uma amostra aleatória das empresas que constituem o universo. Não apenas em decorrência de sua dispersão geográfica, mas também da disposição de seus agentes para o fornecimento das respostas. A amostra selecionada dessa forma mostra-se adequada, já que o propósito da pesquisa não é o de descrever com precisão as características da população, mas sim 0 de permitir uma melhor compreensão do problema e mesmo a construção de hipóteses.

\subsection{Instrumentos de pesquisa}

O instrumento básico para a coleta de dados é o questionário estruturado. Para a sua elaboração, foram realizadas entrevistas com alguns selecionadores de pessoal, com vistas a conhecer melhor seu universo de discurso. Esse procedimento foi essencial para o aprimoramento das alternativas das questões fechadas, já que permitiu sua elaboração com base nas próprias falas dos sujeitos.

Procedeu-se também ao pré-teste do questionário. Para tanto, foram aplicados previamente questionários a cinco selecionadores, com vistas a verificar sua adequação. A pós sua aplicação, foram realizadas entrevistas com os respondentes para verificar dificuldades na compreensão das questões em seu preenchimento. As pessoas que responderam ao questionário foram excluídas da amostra definitiva para evitar possível "contágio".

Foram também realizadas entrevistas não estruturadas com 23 selecionadores de pessoal, com três dirigentes, e com um atendente dos PATs, com o intuito de identificar alguns aspectos de natureza qualitativa não cobertos pelos questionários. Não se estabeleceu previamente a quantidade de entrevistas a ser realizadas, que foram encerradas ao se verificar a "saturação" dos resultados (GLASER; STRAUSS, 1967).

Ainda com o fim de complementar as informações obtidas, os pesquisadores adotaram a técnica da observação 
espontânea nas dependências do PAT. E, à medida do possível, foram obtidos alguns depoimentos de pessoas que lá se encontravam com a finalidade de obter emprego.

\subsection{Anñlise e interpretação dos dados}

As categorias de análise foram definidas previamente, já que o questionário foi estruturado. Procedeu-se, então, à pré-codificação dos dados, tabulados eletronicamente. Para possibilitar a análise, os dados foram dispostos em tabelas, com a apresentação das frequências absolutas e relativas para cada categoria.

Na interpretação, os dados obtidos foram cotejados com os resultados de pesquisas já realizadas, que foram identificadas na etapa de revisão bibliográfica. Procurou-se também identificar nexos entre os resultados obtidos e as formulações teóricas já consagradas pela literatura.

\section{ANÁLISE E DISCUSSÃo DOS RESULTADOS}

\subsection{Caracterização dos empregadores}

As informações referentes à caracterização dos empregadores por si só contribuem para a análise e discussão do significado dos PATs, no contexto das atividades de intermediação de mão de obra. Considere-se, primeiramente, a distribuição dos empregadores que disponibilizam vagas nos PATs (Tabela 1). Essa distribuição não corresponde à participação dos diferentes setores econômicos na Região de G overno de Bragança no que se refere aos vínculos empregatícios, de acordo com a Tabela 2. Embora adotem critérios diferentes de classificação, constata-se que os setores que mais disponibilizam vagas nos PATs são o setor do comércio, seguido pelo de empregadores domésticos. O setor industrial, que corresponde a praticamente $1 / 3$ do total de vínculos empregatícios da região, aparece como o terceiro em relação a esse aspecto.

As vagas disponibilizadas pelos empregadores do setor comercial são em sua maioria vagas que não exigem grau de escolaridade elevado nem muita experiência, o que leva a admitir que os empregadores vêem os PATs como entidades capazes de promover a intermediação de mão de obra de maneira mais efetiva em relação a esses segmentos de população.

Tabela 1: Distribuição dos empregadores segundo o setor em que atuam

\begin{tabular}{lcc}
\hline Área de atuação & $\mathrm{n}$ & $\%$ \\
\hline Comércio & 30 & 30 \\
Empregador Doméstico & 22 & 22 \\
Indústria & 21 & 21 \\
Terceirização & 13 & 13 \\
Consultonia & 9 & 9 \\
Outros & 5 & 5 \\
\hline Total & 100 & 100 \\
\hline
\end{tabular}

Fonte: Elaborado pelos autores, com base nos dados da pesquisa.
Os empregadores domésticos constituem o segundo setor que mais disponibiliza vagas. As vagas mais oferecidas são as de: empregada doméstica, jardineiro, babá, faxineira, diarista, pintor residencial, cozinheira, passadeira, lavadeira e acompanhante. Essas modalidades de vaga também não exigem grau elevado de escolaridade dos candidatos. A maior exigência está relacionada ao tempo de experiência e à idade.

As indústrias - que constituem o setor que mais emprega na região - também utilizam os serviços dos PATs, mas com menor intensidade. As indústrias que mais disponibilizam vagas são as dos setores: têxtil, gráfico, farmacêutico, alimentício, químico e de confecção. Em relação a esse setor, verifica-se que o processo de encaminhamento de candidatos é mais moroso devido às exigências quanto ao perfil da vaga disponibilizada e por se tratar de vagas que exigem mão de obra com qualificação mais elevada. Para preencher essas vagas, é necessária uma seleção mais apurada, pois as competências exigidas para ocupar tais cargos são de cunho especifico e técnico.

Tabela 2: Participação dos vínculos empregatícios por setor econômico na Região de G overno de Bragança Paulista

\begin{tabular}{lc}
\hline Setor econômico & $\mathbf{\%}$ \\
\hline Agropecuária & 6,82 \\
Indústria & 32,61 \\
Indústria & 2,34 \\
Construção civil & 20,67 \\
Comércio & 37,59 \\
\hline Total & 100 \\
\hline
\end{tabular}

Fonte: SEAD E, 2008.

As empresas de terceirização de mão de obra também disponibilizam vagas para suprir suas necessidades de contratação. Essas vagas referem-se principalmente a serviços de limpeza, portaria, recepção, restaurante e telefonia.

As empresas de consultoria também recorrem ao PAT e solicitam 0 envio de candidatos, mas com perfil mais exigente no que tange à qualificação, formação e experiência. A principal vantagem oferecida pelos postos, segundo os consultores, é a sua existência em diversas cidades. A principal vantagem oferecida pelos PATs é a da gratuidade dos serviços, mas os consultores consideram crítico o processo de recrutamento.

A maioria das empresas cadastradas nos PATs é constituída por microempresas e empresas de pequeno porte, administradas geralmente pelos próprios donos, que não possuem um setor de recursos humanos, nem mesmo um processo formal de recrutamento e seleção. Essas empresas, de modo geral, não solicitam candidatos com elevada formação escolar ou ampla experiência na função. Assim, os PATs atendem às necessidades dessas empresas para preencher as vagas disponíveis. Esses resultados aproximam-se dos obtidos nas pesquisas realizadas por Nunes e Guimarães (2003) e contribuem para o fortalecimento da percepção dos PATs 
como importante agente intermediador entre o trabalhador desempregado e as empresas que não dispõem de sistema de recrutamento interno, e que disponibilizam vagas com pouca ou nenhuma exigência. Assim, os PATs podem ser reconhecidos como órgãos que oferecem às empresas um importante apoio no recrutamento e na seleção de candidatos para as pequenas empresas.

As empresas de médio e grande porte que utilizam os serviços de intermediação de mão de obra do PAT geralmente trabalham em paralelo com agências de emprego, além de utilizarem outras fontes de recrutamento, como anúncios em jornal e na internet. As agências privadas têm bancos de currículos melhores que o do PAT e contam com profissionais mais preparados para realizar a entrevista com os candidatos antes de encaminhá-los.

\subsection{Capacitação dos funcionários dos PATs}

A grande maioria dos empregadores considera satisfatória a competência dos atendentes dos PATs. Apenas 11\% os consideram pouco competentes (Tabela 3).

Constata-se que clientes pesquisados, de forma geral, estão satisfeitos com 0 atendimento oferecido pelos PATs. Alguns associam o bom atendimento a algumas características pessoais como: a educação, a presteza, a cordialidade e a competência.

Os funcionários são competentes e educados. A pessoa que me atendeu foi cordial, prestativa e tem potencial para avaliar os candidatos e o perfil das vagas que coloco (Empregador C, G erente de loja).

É muito bom ter o PAT em nossa disposição e contar com este maravilhoso trabalho de pré-seleção. Os funcionários do PAT chegam a ligar para saber se deu certo ou não o candidato, isso demonstra uma preocupação muito positiva (Empregador D, Empregador doméstico).

Embora a maioria dos empregadores admita que os funcionários dos PATs são competentes, foram constatadas algumas manifestações críticas em relação ao seu desempenho:

Elas não têm conhecimento nenhum do que estão fazendo. É um trabalho mecânico, elas não analisam os currículos, mandam pessoas pra gente sem qualificação nenhuma. Acho que deveriam colocar pessoas qualificadas para atender as empresas, pessoas que analisem esses currículos (Empregador E, Gerente administrativo).

O PAT deveria fazer contato conosco e não nós irmos atrás deles. Se o PAT tivesse um contato maior conosco, talvez pudéssemos colocar mais vagas com eles, mas por falta de contato, isso não acontece (Empregador $\mathrm{F}$, Supervisora de RH).

Infelizmente, pelas pessoas que trabalham no PAT não conhecerem Recursos Humanos, elas não encaminham candidatos dentro do perfil. Eu acho assim, quanto mais ter uma pessoa especializada lá dentro, melhor vai ser. (...) As pessoas não estão preparadas para atender, têm boa vontade, mas não estão preparadas (Empregador $\mathrm{G}$, Analista de RH).
Tabela 3: Distribuição da clientela segundo a opinião acerca da competência dos funcionários do PAT

\begin{tabular}{lcc}
\hline $\begin{array}{l}\text { O pinião sobre o nível de competência } \\
\text { dos funcionários }\end{array}$ & $\mathrm{n}$ & $\%$ \\
\hline Muito competentes & 12 & 12 \\
Competentes & 60 & 60 \\
Mais ou menos competentes & 17 & 17 \\
Pouco competentes & 11 & 11 \\
Incompetentes & - & - \\
\hline Total & 100 & 100 \\
\hline
\end{tabular}

Fonte: Elaborado pelos autores, com base nos dados da pesquisa.

Há, no entanto, empresários que reconhecem a competência dos funcionários, mas admitem a dificuldade do PAT para atender às reivindicações das empresas:

Acredito que o PAT possui um banco de dados enorme e muito rico com bons profissionais, porém algumas particularidades da empresa para preenchimentos das vagas, as atendentes não têm condições de atender, encaminhando profissionais fora do perfil, por não conhecer essas particularidades (Empregador $\mathrm{K}$, Analista de RH).

Cabe ressaltar que os PATs não dispõem de um quadro permanente de pessoal. Seus quadros são compostos por funcionários concursados do Estado e por funcionários de diferentes setores da administração pública municipal, com diferentes tipos de vínculo empregatício. Alguns são concursados; outros ocupantes de cargos de confiança, e outros, ainda, encontram-se na condição de estagiários. São, pois, funcionários cuja situação se caracteriza pela transitoriedade e descontinuidade, o que contribui para prejudicar 0 atendimento às empresas e aos trabalhadores e para comprometer a própria imagem dos PATs na condição de organismos vinculados ao Poder Público.

Alguns dos atendentes são funcionários concursados há mais de 20 anos e foram transferidos ou alocados aos PATs quando iniciaram suas atividades na Prefeitura. A faixa etária dos atendentes concursados pela prefeitura e pelo Estado é de 48 a 57 anos. Cabe ressaltar também que há uma elevada rotatividade de pessoal nesses postos de atendimento, o que denota problemas no atendimento aos indivíduos desempregados e aos empregadores.

Essa situação exige ações tanto por parte dos dirigentes dos PATs quanto por parte das Prefeituras, com vistas à adoção de estratégias que contribuam para a melhoria na dinâmica de seu atendimento. Requer-se a utilização de mecanismos capazes de garantir mais efetiva permanência de funcionários em seus postos de trabalho bem como de ações voltadas a treinamento e desenvolvimento. É importante que os funcionários envolvidos no processo de intermediação de mão de obra não se sintam apenas pessoas que se incumbem de tarefas ocasionais, mas agentes do Poder Público incumbidas de contribuir para o equacionamento do problema do emprego.

Uma alternativa para a solução desse problema seria dotar o Serviço Nacional de Emprego de autonomia para 
administrar seu próprio quadro de pessoal, prestando serviços aos estados e municípios que, por sua vez, pagariam pelo serviço prestado. A definição da estratégia das políticas seria dada pelo MTE em nível nacional, e pelas secretarias do trabalho nos planos estaduais e municipais. Com isso, fortalecer-se-ia o caráter nacional do Sistema Público de E mprego, Trabalho e Renda (MO RETTO, 2007).

\section{$4.3 O$ atendimento proporcionado pelos PAT's}

A estrutura física do PAT é reconhecida como adequada pela grande maioria dos empregadores que as conhecem. Entre os empregadores contatados, 65\% citaram como adequada a estrutura física do PAT, $23 \%$ consideram inadequada e 12\% dos clientes não conhecem o espaço físico do PAT.É provável, no entanto, que os trabalhadores não tenham a mesma percepção acerca do atendimento proporcionado, já que com frequência eles permanecem longos períodos em filas que se formam em locais não muito adequados. Mas a infraestrutura dos serviços dos PATs, de modo geral, é mais sofisticada que a de outros serviços proporcionados pelas Prefeituras Municipais, principalmente no que se refere à automação.

Não há como deixar de reconhecer as diferenças entre a qualidade do atendimento proporcionado pelos PATs e pelas agências privadas. A principal diferença entre as agências governamentais e sindicais e as agências privadas está nas estratégias para capturar os demandantes, tais como: localização geográfica; formas de organização das atividades; configuração do layaut das agências; formas de atendimento ao pessoal; diversificação do staff e modalidades de treinamento; e recursos computacionais e sistema de informações que sustentam o trabalho do atendimento (G UIMARÃES, 2005). As agências privadas de emprego são reconhecidas como mais eficientes que os PATs, porque fazem uma seleção mais rigorosa para obter um melhor enquadramento profissional dos trabalhadores, e são mais ágeis no encaminhamento. Mas os serviços prestados por essas agências oneram as empresas, o que explica por que os clientes dos PATs são constituídos em sua maioria por empresas de pequeno porte ou por microempresas.

\subsection{Perfil dos candidatos encaminhados pelos PATs}

Para a grande maioria dos empregadores, os candidatos encaminhados pelo PAT atendem ao perfil da vaga disponibilizada. No entanto, 34\% dos clientes contatados indicam algum tipo de insatisfação com os candidatos encaminhados.

Os empregadores que indicaram a insatisfação com os candidatos são em sua maioria empresas de médio porte no segmento industrial, pois necessitam de mão de obra constituída por pessoas com conhecimentos específicos em determinadas áreas ou com nível de escolaridade mais elevado. É o que indicam alguns depoimentos:

Aqui em Bragança nós temos uma carência muito grande na área técnica, principalmente na área da manutenção, por exemplo, mecânico, eletricista, soldador. É um problema difícil de contornar (Empregador F, Supervisora de RH).
Vaga tem, você vai em qualquer lugar e sempre tem vaga. Você vai nas agências, nas empresas, vê nos jornais na internet. Tá difícil encontrar pessoas capacitadas (Empregador G, Analista de RH).

Alguns clientes mostram-se satisfeitos, indicando existir boa sintonia entre as empresas e o PAT, contribuindo assim para a recolocação de mão de obra de acordo com 0 perfil da vaga. Há, no entanto, clientes que manifestam descontentamento com o nível de qualificação dos candidatos e sugerem alterações nos procedimentos adotados pelo PAT.

O banco de curnículos dos PATs é constituído por trabalhadores com perfis muito diversificados no que se refere a experiência profissional, nível de escolaridade e idade. Por essa razão, atendentes dos PATs informam os candidatos selecionados sobre as exigências e as características da vaga, antes de encaminhá-los, bem como os orientam sobre aspectos de comportamento e postura. Mas nem sempre esse procedimento é suficiente para garantir a adequação do candidato ao perfil definido pela empresa.

Tabela 4: D istribuição da clientela segundo a opinião acerca do perfil dos candidatos encaminhados

\begin{tabular}{lcc}
\hline Opinião acerca do perfil & $\mathrm{n}$ & $\%$ \\
\hline Geralmente atendem & 27 & 27 \\
Na maioria das vezes atendem & 39 & 39 \\
Nem sempre atendem & 14 & 14 \\
Na maioria das vezes não atendem & 17 & 17 \\
Geralmente não atendem & 3 & 3 \\
\hline Total & 100 & 100 \\
\hline
\end{tabular}

Fonte: Elaborado pelos autores, com base nos dados da pesquisa.

A Supervisora do PAT de Itatiba indica diversas dificuldades para a recolocação de pessoal no mercado de trabalho:

As principais dificuldades são a falta de profissionais com a qualificação exigida pelas empresas, a baixa escolaridade e a falta de compromisso e responsabilidade dos candidatos, pois alguns recebem encaminhamento e não comparecem na empresa para fazer a entrevista, outros trabalham alguns dias e não voltam mais, desistem da vaga por serlonge, pelo salário ou outro motivo qualquer (Supervisora do PAT - Itatiba).

Justifica-se o elevado número de clientes que apresentam opinião favorável acerca do perfil dos candidatos (66\%), pois a maioria das vagas disponibilizadas nos PATs são facilmente absorvidas por seus bancos de dados.

Como já exposto, são poucas as vagas colocadas nos PATs por empresas de médio e grande porte. A maior parte dessas vagas exige uma maior qualificação profissional, com habilidades e conhecimentos técnicos, e com elevado grau de instrução. Pode-se observar, no entanto, que o banco de dados dos PATs é constituído por grande contingente de pessoas com baixa qualificação e pouca escolaridade, o que dificulta a (re)colocação nas empresas de médio e grande porte. Segun- 
do Guimarães (2005), o que chama atenção é a quantidade de pobres que procuram emprego usando o sistema público.

Goller (2000) constatou que o contingente de candidatos que buscam os serviços de intermediação de mão de obra dos PATs é constituído em sua maioria por trabalhadores de baixa escolaridade, sem experiência profissional, sem qualificação específica e com pouco tempo de experiência comprovada. Assim, para esses trabalhadores, os PATs são seu elo com o mercado de trabalho.

Existem grupos de indivíduos com maiores dificuldades de acesso às informações do mercado de trabalho e menores recursos, o que impossibilita o uso de outros meios alternativos de busca de emprego. Segundo Radzinski (2008), as agências públicas, em sua maionia, estão voltadas para atender à base do mercado de trabalho, ou seja, a oferta e demanda por postos de trabalho que exigem menor qualificação e oferecem salánios mais baixos. Guimarães (2005) afirma que 0 que verdadeiramente chama a atenção é como são muito pobres os que procuram emprego usando o sistema público. Assim, a própria formação e a baixa qualificação desses indivíduos pode ser um fator de defesa da existência de um serviço público de intermediação, quando a colocação de trabalhadores desse perfil não é do interesse de agências privadas de emprego e nem mesmo esses trabalhadores pertencem ao perfil de vagas of erecidas por essas empresas.

G eralmente os clientes-empresas que dispõem de vagas que exigem maior qualificação não as disponibilizam exclusivamente nos PATs, recorrendo também às agências privadas de emprego. As exigências das empresas para o provimento dessas vagas faz com que muitos dos trabalhadores inscritos nos PATs encontrem dificuldade para recolocação no mercado de trabalho. Essa situação, aliada à morosidade no encaminhamento dos candidatos às empresas, conspiram contra os PATs; já esses programas tendem a perder a concorrência com as fontes privadas de recrutamento, ou conseguem se mostrar mais eficientes, pelo menos em relação a candidatos com mais elevado nível de qualificação profissional.

\subsection{O papel dos PAT's}

Os dados obtidos permitem de certa forma definir 0 perfil dos clientes-empresas que buscam os PATs como fonte de recrutamento para suprir suas necessidades de pessoal. São, principalmente, micro e pequenas empresas que não possuem setor específico para o recrutamento e a seleção dos candidatos. Em sua maioria pertencem aos setores comércio e prestação de serviços. A principal razão que os leva a dispor suas vagas nos PATs, por sua vez, é a gratuidade dos serviços oferecidos. Muitas das micro e pequenas empresas que oferecem vagas que não exigem elevada qualificação têm dificuldade para contratar serviços de agências privadas, 0 que indica que os PATs também desempenham importante papel social. Como constituem a única possibilidade de atuar como intermediador de mão de obra com essas empresas, não é despropositado admitir que os PATs atuam também como entidades de apoio às micro e pequenas empresas.
Procuram os serviços de intermediação dos PATs ofertantes e demandantes de trabalho. Os PATs têm, portanto, papel relevante como intermediador entre 0 trabalhadore as empresas, sobretudo para as micro e pequenas que não dispõem de um departamento de recursos humanos, e que, por serem de modo geral administradas diretamente pelo empregador, acabam por não ter um processo sistematizado de seleção e recrutamento de pessoal (NUNES, 2003). Assim sendo, a intermediação de mão de obra proporcionada pelos PATs possibilita a essas empresas o recrutamento e a seleção de candidatos como um serviço de apoio.

O papel da intermediação de mão de obra é assegurar a eficácia da intermediação e colocação dos trabalhadores no mercado de trabalho, no sentido de ajudá-los a encontrar um emprego, captar as vagas oferecidas pelos empregadores e encaminhar os trabalhadores cadastrados para o mercado de trabalho.

D essa forma, aintermediação realizada pelo SINE, além do papel precípuo de auxiliar o trabalhador na obtenção de um emprego, assume, também, o papel de diagnosticar suas carências pessoais e profissionais relacionados com as possibilidades de obtenção de emprego, podendo encaminhá-lo à qualificação profissional, para alternativas de geração de renda ou, ainda, para outros serviços públicos (CACCIAMALI; SILVA; MATOS, 1998). As agências privadas de emprego têm sistemáticas de atendimento diferenciadas entre si e em relação aos PATs.

\section{CONCLUSÃO}

Conclui-se que os PATs se identificam principalmente com a intermediação de mão de obra pouco qualificada. A maioria dos candidatos que os procuram são pessoas de baixa renda e baixo nível de escolaridade. Os bancos de dados dos PATs, por sua vez, são constituídos por currículos de pessoas que não preenchem muitas das exigências das empresas, sobretudo em relação à qualificação e ao tempo de experiência profissional. Isso pode ser considerado, por um lado, como deficiência dos PATs, que não podem ser reconhecidos pelas empresas como entidades adequadas para 0 suprimento de suas necessidades de pessoal nos mais diversos níveis. Mas pode, por outro lado, estar indicando a relevância social dos serviços dos PATs. Com efeito, por conta exatamente dessa situação é que os PATs podem ser reconhecidos como importantes elementos do processo de re(colocação) no mercado de trabalho. Para grandes contingentes de trabalhadores, os PATs constituem o principal - se não o único - elo com o mercado de trabalho, posto que, para as agências privadas de colocação, trabalhadores com esse perfil tendem a ser ignorados, já que não atendem às exigências de seus clientes-empresas.

Conclui-se também que os clientes-empresas que buscam os PATs são, principalmente, micro e pequenas empresas que não têm estrutura suficiente para manter um setor específico para tratar do suprimento de pessoal. A principal atratividade dos PATs é, pois, a gratuidade de seus serviços, 
já que essas empresas têm dificuldade para contratar serviços de empresas privadas. D aí tornar-se legítimo considerar que os PATs não funcionam apenas como entidades de atendimento ao trabalhador, mas também como entidades de apoio a pequenas e micro-empresas.

Conclui-se, por fim, que, a despeito de sua institucionalização e do reconhecimento de sua atuação, os PATs dependem de recursos humanos e materiais fornecidos principalmente pela esfera municipal de gestão. Assim, a situação dos funcionários dos PATs tende a se caracterizar pela transitoriedade e descontinuidade, prejudicando 0 atendimento aos trabalhadores e às empresas, e contribui para o comprometimento da imagem das entidades.

A identificação dos limites da presente pesquisa, por sua vez, conduz ao oferecimento de sugestões a pesquisadores dispostos a investigar os múltiplos aspectos da intermediação de mão de obra. Sugere-se a realização de amplos levantamentos voltados à identificação não apenas de percepções de clientes-empresas e de funcionários dos PATs, mas também de trabalhadores dos mais diversos segmentos.

Também se recomenda a realização de estudos de natureza documental. Como os dados estão disponíveis no formato eletrônico, poderiam ser organizados de forma a possibilitar aidentificação de pontos críticos do processo de intermedia ção de mão de obra. E já que os dados obtidos mediante entrevistas não estruturadas e depoimentos pessoais mostraramse particularmente ricos, recomenda-se ainda a realização de pesquisas de caráter qualitativo, capazes de captar os fenômenos sob o ponto de vista dos atores envolvidos.

Assim, sugere-se a realização de pesquisas sob o modelo da grounded theary, cuja principal vantagem é a de proporcionar a construção de teorias substantivas, não com o propósito de generalizar conhecimentos, mas com o de proporcionar um conhecimento mais adequado de uma realidade que não é delimitada necessariamente pela espacialidade ou pela temporalidade. Essas teorias fundamentadas nos dados possibilitam a construção de teorias substantivas referentes a alguns dos múltiplos aspectos do processo de intermediação de mão de obra.

\section{REFERÊNCIAS}

AZERED 0, B. Pdíticas púbicas de emprega a experiência brasileira. Campinas: ABET, 1998.

AZERED 0, B.; RAMOS, C. A. Políticas públicas de emprego: experiências e desafios. PlangjamentoePdíticasPúblicas Brasilia, n. 12, p. 91-114, jun.-dez. 1995.

BORGES, M. A. Uma contribuição ao debate das políticas públicas de emprego: o sistema nacional de emprego. RexistaABET, v. 3, n. 1. 2003. CACCIAMALI, M. C.; SILVA, G. B.; MATOS, F. Sistema nacional de emprego: desempenho interestadual. In: OLIVEIRA, M. A. de (O rg.). Reforma do Estado e Pdíticas Públicas de Emprego no Brasil. Campinas: UNICAMP, 1998.

CHAHAD, J. P. Z.; CACCIAMALI, M. C. MecadbdetrabalhonoBrasil: novas práticas trabalhistas, negociações coletivas e direitos fundamentais no trabalho. São Paulo: LTR, 2003.

DIEESE - DEPARTAMENTO INTERSINDICAL DE ESTATÍSTICA E ESTUD OS SÓ CIO-ECONÔ MICO S. A situra̧ão dotrabalho noBrasil. São Paulo: DIEESE, 2001.
DUPAS, G. Tensõescontemporân€s entreopúbicoeoprivada São Paulo: Paz e Terra, 2003.

FÉ RRER, E. Seminánio estadual do sistema público de empreeg, trabalho, renda edsenvdvimentodoPiaú. Entrevista em 24 mar. 2006. D isponível em: <http:/ / www.pi.gov.br/ entrevista. php?id=18211>. A cesso em: 17 jul. 2007.

FO LHA ONLINE. Saúde é o principal problema do país para 25\% da população. Fdha Online, 5 dez. 2008. D isponível em: <www1.folha.uol. com.br/ folha/ brasil/ ult96u475551.shtml>. Acesso em:22 dez. 2008. FUNDAÇÃO SISTEMA ESTAD UAL DE ANÁLISE DE DAD OS. Sistemadeinformaçaes dosmumiápios paulistas- IMP. São Paulo: SEADE, 2008. Disponível em: <www.seade.gov.br/ produtos/ imp/ >. Acesso em: 18 dez. 2008.

G O LLER, T. Intemediaçãodemãodedbra noSind RS emuma pespeetiva de sistema público de emprego. $136 \mathrm{f}$. D issertação (Mestrado em Administração) - UFRG. Porto Alegre, 2000.

GUIMARÃES, N. A. Os territórios do (des)emprego: clusters de intermediadores e estruturação social do mercado de trabalho. In: ENCONTRO ANUAL DA ANPOCS, 29, 2005, Caxambu. Anais.. São Paulo: ANPOCS, 2005.

IPEA - INSTITUTO DE PESQ UISA ECONÔMICA APLICADA. O estadbdeuma naçãa mercado de trabalho, emprego e informalidade. Rio de Janeiro: IPEA, 2006.

MARCHI, C. Saúde é maior preocupação para 3 em cada 4 paulistanos. OEstadbdeSãoPaulo 31 ago. 2008. D isponível em: <http:/ / txt4. estado. com.br/ editorias/ 2008/ 08/ 31/ pol-1.93.11.20080831.1.1.xml>. Acesso em: 18 dez. 2008.

MO RETTO, A. J. O sistemapúblicodeempregonoBrasil: uma construção inacabada. 172 f. Tese (D outorado em Ciências Sociais) - Unicamp. Campinas, 2007.

NUNES, C. A. A intemediação db traballhono capitalismo- os desafios da experiência brasileira. Dissertação (Mestrado em Economia Social e do Trabalho) - UNICAMP. Campinas, 2003.

ORGANISATION FOR ECONOMIC CO-OPERATION AND DEVELO PMENT - OECD. The OECD jdos study: facts, analysis, strategies. Paris: OECD, 1994.

PAMPLONA, J. B. Estudo das empresas prestadoras de serviços de seleção, agenciamento e locação de mão-de-obra temporária do G rande ABC Paulista. In: G UIMARÃES, N. A. Getão loal, empregabilidadee equidadedegônero eraça: um experimento de política pública na Região do ABC Paulista. Relatónio Final. Santo André: FAPESP/ CEBRAP/ PMSA/ CEERT/ ELAS, ago. 2003. D isponível em: <http:/ / www.fflch.usp.br/ sociologia/ nadya>. Acesso em: 20 out. 2007.

POCHMANN, M.; MORETTO, A. Retomada do emprego numa economia em marcha lenta: implicações para as políticas públicas de mercado de trabalho. In: ENCONTRO NACIONAL DE ESTUD O S PO PULACIO NAIS, 14. Caxambu, 2004. Anais... Caxambu: ABEP, 2004.

RAD ZIN SK I, V. Intemediaçãodemãodedbranosistemapúbicodeempreeg no Paraná: um estudo de caso. 156 f. Dissertação (Mestrado em Sociologia) - UFPR. Curitiba, 2008.

SINE - SISTEMA NACIONAL DE EMPREGO. Relatónios estatísticos D isponível em: <http:/ / www.mte.gov.br/ sine/ relatorios. asp>. Acesso em: 17 jul. 2008.

SO UZA, F. F. Avaliação do SINE na Bahia. Revista Bahia Análise \& Dados, Salvador, p. 183-200, dez. 2003.

Data de Submissão: 22/ 05/ 2009

Data de Aprovação: 12/ 12/ 2010 